\title{
Nutritional Benefits of Citrus Fruits
}

\author{
Waleed Fouad Abobatta* \\ Department of Citrus, Horticulture Research Institute, Egypt
}

*Corresponding author: Waleed Fouad Abobatta, Department of Citrus, Horticulture Research Institute, Agriculture Research Center, Giza, Egypt.

To Cite This Article: Waleed Fouad Abobatta. Nutritional Benefits of Citrus Fruits. Am J Biomed Sci \& Res. 2019 - 3(4). AJBSR.MS.ID.000681. DOI: 10.34297/AJBSR.2019.03.000681

Received: May 20, 2019 | Published: June 14, 2019

\begin{abstract}
Citrus is an evergreen shrub or small trees grown in tropical, sub-tropical and temperate regions, citrus including Oranges, Mandarins, Tangerines, Limes, Grapefruits, Lemons, and Citrons. Citrus fruits are a precious resource of phytochemicals which are beneficial for the human body, like vitamin C, Vitamins B, potassium, phosphorous, and other elements, also, there are various active compounds extracted from citrus fruits used against heart diseases, and in treatments of hypertension, also, it is used as anticancer, inflammation, antiviral, antibacterial and antifungal activity. Citrus juice contains enzymes considered a natural tool for obesity control and contained a range of different protein which burns human fats.
\end{abstract}

Keywords: Citrus; Grapefruit Vitamin C; Heart disease; Obesity control

\section{Introduction}

Citrus is an evergreen shrub or small trees belonging to the family of Rutaceae, grown in tropical, sub-tropical and temperate regions, citrus including oranges, Mandarins, Tangerines, Limes, Grapefruits, Lemons, and Citrons, as well as many hybrids and varieties [1]. Fruits reach to maturity stage between mid-December and April in the Northern Hemisphere particularly oranges and grapefruit, also, the fruit available around the year approximately.

Citrus fruit one of the most important fruits all over the world, due to health-related elements and valuable components which involves vitamins $\mathrm{C}$, carotenoids, flavonoids, pectin, Calcium, Potassium...etc. Citrus fruits considered a precious resource of soluble and insoluble fiber with numerous benefits such as removing the toxic effects in the body [2]. Fiber improves the gastric adsorption in the small intestine, decrease the energy absorption process, and maintain the performance of the bile duct and liver. Citrus fruit contained a higher level of flavonoids, terpenes, phytonutrients, and range of phenolic compounds, vitamins $\mathrm{C}$ and carotenoids.

There are various active compounds extracted from citrus fruits like lemons, grapefruits, sweet oranges, used in treatments of hypertension, other citrus species considered a source of potential antioxidant against heart diseases, anticancer, inflammation, antiviral, antibacterial and antifungal activity. Each part of citrus fruit contains active ingredients, it is present in fruit flush, juice, even peel and seed depend upon varieties and maturity stage.

\section{Botanical of Citrus}

Citrus is a genus from family Rutaceae which containing 130 genera with several important varieties, Citrus is an evergreen aromatic shrub or small trees native to South-East Asia, but now cultivated in subtropical and temperate region all over the world; Around $70 \%$ of the world's total citrus production is grown in the Northern Hemisphere, in particular, Mediterranean region and the United States, although Brazil and South Africa in Southern Hemisphere. Global citrus production reaches to 124.25 million ton in 2016 China ranking as the biggest producer of citrus followed by Brazil, India, USA, Spain, Mexico, Egypt, Iran, and South Africa [3].

Citrus fruit divided into different groups [1] as follow:

a. Sweet Orange (Citrus sinensis L.): including Common orange, Navel orange, Blood orange, and Valencia orange.

b. Sour orange (Citrus aurantium): bitter orange and their varieties

c. Mandarin and Tangerine (Citrus reticulata of Swingle) or (Citrus deliciosa of Tanaka): this group are category of easyto-peel citrus, involves varieties with yellow and orange peel, like Satsuma mandarin, Dancy tangerine, some varieties may ripen as early as December such as Clementine and satsuma mandarin, however, late varieties may be harvested at August or September as Murcott and Pixie mandarins. 
d. Lemon (Citrus limon): Fruits mature throughout year, this group including Eureka, Lisbon and Meyer lemon.

e. Lime (Citrus aurantifolia): including Mexican lime, Indian lime, Tahitian lime, Bearss lime, and key lime, the fruit mature all-over the year.

f. Other kinds: like Citron, Kumquat, and Pomelos.

These citrus fruits are the precious resource of phytochemicals which are beneficial for the human body as vital bioactive medicines, Phytochemicals are naturally present in citrus juices and play a role in physiological functions and metabolic change of human body [4], also, Citrus fruits and juice has a unique value of essential nutrients, and these nutrients protect against several chronic diseases [5]. Citrus has potential health benefits like antimicrobial, antiinflammatory, antiviral and anticancer, besides that, Citrus juice contains a lower amount of cholesterol that helps for diabetes patients [6].

\section{Chemical composition of Citrus Fruits}

There are valuable natural chemicals in citrus fruits, it is an excellent source of different elements and vitamins required for the human body, including C vitamins, B vitamins, potassium, phosphorous, and other elements (Table 1).

Table 1: Chemical composition of Citrus Fruits (per $100 \mathrm{~g}$ of edible portion).

\begin{tabular}{|c|c|c|c|c|c|c|}
\hline Component & C. Sinensis & C. paradisi & C. reticulate & C. aurantifolia & C. aurantium & C. Limon \\
\hline Moisture (g) & 88.4 & 88.5 & 87.8 & 84.6 & 87.6 & 85 \\
\hline Protein (g) & 0.8 & 1 & 0.9 & 1.5 & 0.7 & 1 \\
\hline Fat (g) & 0.3 & 0.1 & 0.3 & 1 & 0.2 & 0.9 \\
\hline Fibre, $g$ & 0.5 & - & - & 1.3 & 0.3 & 1.7 \\
\hline Carbohydrates (g) & 9.3 & 10 & 10.6 & 10.9 & 10.9 & 11.1 \\
\hline Minerals (g) & 0.7 & 0.4 & 0.4 & 0.7 & 0.3 & 0.3 \\
\hline Calcium (mg) & 40 & 30 & 50 & 90 & 26 & 70 \\
\hline Phosphorous & 30 & 30 & 20 & 20 & 20 & 10 \\
\hline Iron (mg) & 0.7 & 0.2 & 0.1 & 0.3 & 0.3 & 2.3 \\
\hline Thiamine (mg) & - & 0.12 & 40 & 0.02 & - & 0.02 (in juice) \\
\hline Riboflavin (mg) & - & 0.02 & - & 0.03 & - & 0.01 (in juice) \\
\hline Niacin (mg) & - & 0.3 & - & 0.1 & - & 0.01(in juice) \\
\hline Vitamin C (mg) & 50 & - & 68 & 63 & 30 & 39 (in juice) \\
\hline Carotene, $\mu \mathrm{g}$ & - & - & 350 & 15 & 1104 & - \\
\hline Energy, K cal & 43 & 45 & - & 59 & 48 & 57 \\
\hline
\end{tabular}

\section{Phytochemicals in citrus fruits}

Citrus phytochemicals distribution in various parts of fruits, phytochemicals exhibit the antibacterial, antiviral, antifungal, anticarcinogenic, antithrombotic or anti-inflammatory properties, also, it assists in lowering cholesterol. These active compounds are phenols, carotenoids, phytoestrogen and sulfides having antioxidative potential, and marked as health promoter due to their broad spectrum in the human body [8].

Flavonoids: Citrus fruit is a rich resource of flavonoids with many physiological properties involved in controlling antiviral activity and anti-microbial activity. They are present in the form of the glycoside or aglycone, especially in citrus juices as glycosyl derivatives (flavonoid glycosides, FGs) which showed potential health benefits for the human body [9]. It had excellent potential to control many chronic diseases and suppressed the infectious in the body. Hesperidin and quercetin involve in control of herpes virus, parainfluenza and polioviruses [10]. The naringin metabolites are a rich source of natural antimicrobials activity against the positive and negative bacteria [11]. Mandarin fruit has the highest content of flavonoids, followed by common oranges and Grapefruit, however, there is no any flavonoids in lemon fruit.

Table 2: Major group of Carotenoids found in citrus fruits.

\begin{tabular}{|c|c|c|c|c|c|c|}
\hline Carotenoids mg/110 g & Mandarin & Grapefruit & Common Oranges & Valencia Oranges & Tangerine & Lemon \\
\hline Auroxanthin & - & - & 0.23 & - & - \\
\hline Cis $\beta$-carotene & 11 & - & - & - & - \\
\hline$\alpha$-Carotene & 20 -Dec & 1 & $19-20$ & - & 1 \\
\hline Cryptoxanthin & 20 -Oct & 3.3 & - & - & - \\
\hline$\beta$-Cryptoxanthin & - & 150 & - & - & - \\
\hline Lutein & $20-50$ & 9.5 & 27 & $20-35$ & - \\
\hline Lycopene & - & 1 & - & $4-M a r$ & - \\
\hline
\end{tabular}


Carotenoids: The primary role of carotenoids pigment compounds to protect the various diseases of the human body and control-health-related elements; sweet orange, mandarin's and grapefruits are a rich source of carotenoids. Lutein and zeaxanthin are rich sources of citrus which are suitable for eyes and immunes system of the body. A vibrant source of carotenoids present in Cara navel oranges and mandarin fruits. The comparison of significant carotenoids present in citrus fruits (Table 2) clear that, Mandarins fruit has higher values followed by Grapefruit, then, orange fruits, however, lemon fruits haven't any carotenoids in their components.

Essential oil: Citrus species considered a rich source of aromatic compounds, particularly, fruit peel, citrus fruit have about 400 compounds of volatile and nonvolatile compounds. From ancient time essential oil of used for medicine and aromatic purpose, nowadays, the essential oil used in different pharmacy and cosmetic and other related industries, for their antispasmodic and antimicrobial activity [12].
Mucilage: Mucilage is present in the seed, peel, and pulp of citrus fruits, it is a fiber-like and forms a gel-like structure which mixed with water. Citrus fruits have a higher ratio of fiber (soluble and insoluble) which reducing cholesterol levels, besides that; citrus seeds have psyllium, with improving the digestives system, and enhancing the elimination of cholesterol [13].

Tannins: The grapefruit, lemon, and lime fruits have a higher content of tannins compounds than other citrus fruits, this tannins play an important role in stop diarrhea and decrease bleeding and controls other extreme secretions of the body [14].

\section{Some health benefits of citrus}

Citrus fruits have a wide range of biological activity for maintaining body health (Table 3). Also, Sweet orange and lemon fruits have a vast range of bioactive compounds which reported a $60-70 \%$ control of liver diseases [7].

\begin{tabular}{|c|c|}
\hline \multicolumn{1}{|c|}{ Table 3: Role of different components in citrus fruit. } \\
\hline Component & Health promoting role \\
\hline Ascorbic acid (Vitamin C) & Formation of connective tissues, collagen, absorption of iron and properties of antioxidants \\
\hline Thiamin (Vitamin B1) & Heart, brain, nervous system, cofactor in gastrointestinal, muscular functions \\
\hline Riboflavin (Vitamin B2) & Reduction reactions and coenzyme in oxidation \\
\hline Niacin (Vitamin B3) & Its balance the body, fluid, metabolism, hemoglobin \\
\hline Piridoxina (Vitamin B6) & It plays a role in an acid, nucleic acid and metabolism balance \\
\hline Folic acid (Vitamin B9) & Role in fluid system and assists in nervous system \\
\hline Potassium (K) & It is main part in bones, teeth and major role in metabolism \\
\hline Calcium (Ca) & It is involving in DNA and part of energy distributions \\
\hline Phosphorus (P) & Muscles contraction \\
\hline Magnesium (Mg) & It involves in metal enzymatic activity and fat metabolism \\
\hline Manganese (Mn) & Blood circulation and metabolism in body \\
\hline Zinc (Zn) & Antioxidants role in body process \\
\hline Selenium (Si) & Copper is trace element for essential in health \\
\hline Copper (Cu) & Its balance the human body and nerves and muscles functions \\
\hline Sodium (Na) & \\
\hline
\end{tabular}

However, Citrus juice particularly grapefruit juice contains enzymes particularly P-45 enzyme which considered a natural tool for obesity control and contained a range of different protein which burns human fats [13].

The lemon fruits have numerous bioactive compounds, and the juice of lemon possesses more than 200 compounds which involve regulators of the human body [4]. However, lemon and sweet orange juices have a wide range of bioactive compounds controlled about $60-70 \%$ of liver diseases through control lipids.

\section{The main health benefits of citrus}

Anti-carcinogenic properties: Citrus flavonoids possess anticarcinogenic and anti-tumor activities [6]

Cardiovascular properties: Citrus flavonoids show an antiadhesive and antiaggregation action against red cell clumping [15]
Hyperglycemia: Citrus flavonoids play important roles in preventing the progression of hyperglycemia, partly through binding with starch, increasing hepatic glycolysis and the glycogen concentration, and lowering hepatic gluconeogenesis [16]

Anti-inflammatory, Antiallergic and Analgesic activity: Citrus flavonoids like hesperidin, diosmin, quercetin, and other flavonoids have shown dose-dependent anti-inflammatory activity by influencing metabolism of arachidonicacid and histamine release [17].

Anti-microbial activity: One of the properties of flavonoids with their physiological action in the plants are their antifungal and antiviral activity [11].

Anti-anxiety, antidepressant, and antiallergic activity: Apigenin shows antidepressant activity, some flavonoids show antiallergic [14]. 
Citrus and lipids control: Many clinical studies reported that the citrus juice is helpful for control higher cholesterol and major lipid problem of the human body, due to the higher content of soluble and insoluble fiber in citrus juice [18].

\section{Conclusion}

Citrus fruits are known to their beneficial biological activities for the human body, Citrus fruits are available around the year, Citrus fruits and their components have a rich source of flavonoids, carotenoids, and bioactive compounds which used in treatment of hypertension, also, there are active compounds extracted from citrus fruits used against heart diseases. However, Citrus juice contains enzymes considered a natural tool for obesity control and contained a range of different protein which burns human fats.

\section{References}

1. Waleed FA (2019) Citrus Varieties in Egypt: An Impression. International Research Journal of Applied Sciences 1: 63-66.

2. Pragasam, SJ, Rasool M (2013) Dietary component p-coumaric acid suppresses monosodium urate crystal-induced inflammation in rats. Inflammation Research 62(5): 489-498.

3. (2017) FOA Statistical Bulletin.

4. Waseem A, Rafia A (2019) Citrus: An Ancient Fruits of Promise for Health Benefits.

5. Lucker J, Tamer MK, Schwab W, Verstappen FWA, Plas LHWV, et al. (2002) Monoterpene biosynthesis in lemon (Citrus limon). cDNA isolation and functional analysis of four monoterpene synthases. European Journal of Biochemistry 269(13): 3160-3171.

6. Li S, Lo CY, Ho CT (2006) Hydroxylated polymethoxy flavones and methyl flavonoids in sweet orange Citrus sinensis flavedo. Journal of Agricultural and Food Chemistry 54(12): 4176-4185.

7. Sidana J, Saini V, Dahiya S, Nain P, Bala S (2013) A Review on Citrus "The Boon of Nature". Int J Pharm Sci Rev Res18(2): 20-27

8. Kuo S (1996) Ant proliferative potency of structurally distinct dietary flavonoids on Human Colon Cancer Cells. Cancer Letters 110(1-2): 4148.
9. Loizzo MR, Tundis R, Bonesi M, Menichini F, De Luca D, et al. (2012) Evaluation of Citrus aurantifolia peel and leaves extracts for their chemical composition, antioxidant and anti-cholinesterase activities, J Sci Food Agric 92(15): 2960-2967.

10. Kandaswami C, Perkins E, Soloniuk DS, Drzewiecki G, Middleton E (1991) Antiproliferative effects of Citrus flavonoids on a human squamous cell carcinoma in vitro. Cancer Letter 56(2): 147-152.

11. Calomme M, Pieters L, Vlietinck A, Berghe DV (1996) Inhibition of bacterial mutagenesis by Citrus flavonoids. Planta Medica 62(3): 222226 .

12. Jung UJ, Lee MK, Jeong KS, Chol MS (2004) The hypoglycemic effects of hesperidin and naringin are partly mediated by hepaticglucose regulating enzymes in $\mathrm{C} 57 \mathrm{BL} / \mathrm{KsJ}-\mathrm{db} / \mathrm{db}$ Mice. Journal of Nutrition 134(10): 2499-2503.

13. Ono E, Inoue J, Hashidume T, Shimizu M, Sato R (2011) Anti-obesity and anti-hyperglycemic effects of the dietary Citrus limonoidnomilin in mice fed a high-fat diet. Biochem Biophys Res Commun 410(3): 677-681.

14. Matsuda H, Yano M, Kubo M, Iinuma M, Oyama M, et al. (1991) Pharmacological study on Citrus fruits. II. Anti-allergic effects of fruits of Citrus unshiu Markovicj (2) on flavonoids components. Yakugaku Zasshi 111(3): 193-198.

15. Robbins RC (1974) Action of flavonoids on blood cells: Trimodal action of flavonoids elucidates their inconsistent physiologic effects. International Journal for Vitamin and Nutrition Research 44(2): 203216.

16. Shen W, Xu Y, Lu YH (2012) Inhibitory effects of Citrus flavonoids on starch digestion and antihyperglycemic effects in HepG2 cells. J Agric Food Chem 60(38): 9609-9619.

17. Galati EM, Monforte MT, Kirjavainen S, Forestieri AM, Trovato A, et al. (1994) Biological effects of hesperidin, a Citrus flavonoid (note I): Antiinflammatory and analgesic activity. Farmaco 40(11): 709-712.

18. Kurowska EM, Spence JD, Jordan J, Wetmore S, Freeman DJ, et al. (2000) HDL cholesterol raising effect of dietary orange juice in subjects with hypercholesterolemia. American Journal of Clinical Nutrition 72(5): 1095-1100. 